\title{
ÉTICA E ANIMAIS - REFLEXÕES DESDE O IMPERATIVO DA ALTERIDADE
}

Ricardo Timm de Souza

RESUMO - O artigo tem como objetivo propor a viabilidade de uma proposta de ética que contemple os animais não-humanos como "interlocutores" possíveis de um modelo ético mais geral a partir da inspiração da ética da Alteridade de E. Levinas.

PALAVRAS-CHAVE - Ética. Animais. Racionalidade. Alteridade.
ABSTRACT - The article seeks to render feasible a proposal of ethics that regards "nonhuman animals" as prospective "interlocutors" within a broader ethical model inspired by E. Levinas's ethics of alterity.

KEY WORDS - Ethics. Animals. Rationality. Alterity.

"Die Philosophie ist eigentlich dazu da, das einzulösen,

was im Blick eines Tieres liegt"

Theodor ADORNO ${ }^{1}$

\section{Introdução}

A frase de Adorno em epígrafe traduz simultaneamente uma dimensão de clarificação dos termos em que a temática da relação entre a ética e os animais se coloca a partir de parâmetros da ética da alteridade e uma outra dimensão, poderíamos chamá-la abissal, denunciadora da complexidade da questão que pretendemos abordar apenas introdutoriamente no presente texto. ${ }^{2}$

PUCRS, Porto Alegre.

Apud JÄGER, Lorenz. Adorno - Eine politische Biographie, p. 11. Optamos pela seguinte tradução: "A filosofia existe propriamente para fazer justiça ao que se dá no olhar de um animal".

As bases argumentativas gerais do presente texto, que não serão aqui referidas em detalhe para evitar o excesso de citações, encontram-se especialmente em nossos livros Totalidade \& Desagregação. Sobre as fronteiras do pensamento e suas alternativas; O tempo e a Máquina do Tempo - estudos de filosofia e pós-modernidade; Existência em Decisão - uma introdução ao pensamento de Franz Rosenzweig; Sujeito, Ética e História - Levinas, o traumatismo infinito e a crítica da filosofia ocidental; Sentido e Alteridade - Dez ensaios sobre o pensamento de Emmanuel Levinas; Razões plurais - itinerários da racionalidade ética no século XX; Em torno à Diferença - aventuras da alteridade na complexidade da cultura contemporânea e, especialmente, em Ética como fundamento uma introdução à ética contemporânea, bem como nos artigos e capítulos "Justiça, liberdade e alteridade ética. Sobre a questão da radicalidade da justiça desde o pensamento de E. Levinas", "Ética e Ambiente. Por uma nova ética ambiental" e em vários outros textos inéditos. Para referências bibliográficas completas, cf. Referências, ao fim do texto.

\begin{tabular}{|l|l|l|l|l|l|}
\hline VERITAS & Porto Alegre & v. 52 & n. 2 & Junho 2007 & p. 109-127 \\
\hline
\end{tabular}


A primeira questão que se coloca parece ser também uma das principais: afinal, quem é o animal? Essa questão parece imprópria em muitos sentidos, pois nos acostumamos, ao longo dos séculos, a coisificar o que estabelecemos como correlato de nosso intelecto todo-poderoso; a pergunta poderia soar, no máximo, como "o que é um animal". E, não obstante, pretendemos argumentar neste texto em favor de uma radical reordenação axiológica, que estabeleça os animais como também depositários de uma estrutura correlacional de alteridade irredutível à simples simetrização do logos classificador.

Para tanto, recorremos aqui a uma leitura de estilo arqueológico, focando, exatamente, a estruturação do pensamento classificante lógico/ordenador pela anulação da diferença real. Embora tenhamos já abordado este tema em muitas oportunidades e publicado textos que representam estágios de aperfeiçoamento paulatino de nosso argumento, cabe aqui retomá-lo, e por uma razão muito simples: a especificidade da temática que aqui nos ocupa, os animais. Pois, se é verdade que um tal argumento pode assumir aguda pertinência no que se refere à especificidade do ser humano - e muitas obras têm sido escritas, neste recémfindo século XX, a abalizar uma tal constatação ${ }^{3}$-, bem como se é verdade que, mutatis mutandis, a articulação geral das idéias encontra eco claro no que diz respeito à realidade estética ${ }^{4}$ e às realidades ambientais ${ }^{5}$ em sentido mais amplo, não menos verdade é que o exposto se aplica de forma cabal aos animais, por motivos que esperamos esclarecer ao longo do texto e, especialmente, nas conclusões.

\section{Da diferença à objetificação}

Como já enunciamos, a presente seção se inscreve em uma linha de trabalhos já antiga. Seus temas essenciais já estão presentes em nosso artigo "Da neutralização da diferença à dignidade da Alteridade: estações de uma história multicentenária", apresentado originalmente no Colóquio sobre o Pensamento Judaico Contemporâneo, USP/Universidade Hebraica de Jerusalém, São Paulo, agosto de 1999, e publicado originalmente em Sentido e Alteridade - Dez ensaios sobre o pensamento de Emmanuel Levinas, sendo posteriormente revisto, desenvolvido e reapresentado sob diversos formatos em eventos igualmente muito diversos nas

Apenas como referência inicial e com o intuito de permanecermos em nosso âmbito específico de abordagem "antropológica" da questão, vejam-se entre outros nossos Fontes do humanismo latino A condição humana no pensamento filosófico moderno e contemporâneo, "Três teses sobra a violência", "Das neue Denken und die Ermöglichung des Friedens - Franz Rosenzweig und Emmanuel Levinas im Zentrum der Ereignisse des 20. Jahrhunderts", "Humanismo e alteridade. A filosofia frente à radicalidade do desafio humano", "A dignidade da pessoa humana: uma visão contemporânea", "Nós e os outros. Sobre a questão do humanismo, hoje", bem como o clássico de Levinas, Humanismo do outro homem.

No sentido da nota acima, cf. nosso Metamorfose e Extinção - sobre Kafka e a patologia do tempo.

Cf. nossos Em torno à Diferença - aventuras da Alteridade na complexidade da cultura contemporânea; "Ética e Ambiente. Por uma nova ética ambiental", bem como as coletâneas Ciência e Ética - os grandes desafios e Fenomenologia hoje III - bioética, biotecnologia, biopolítica. 
áreas da filosofia, da literatura e do direito; sua última retomada, sob enfoque bastante diverso do original, se encontra em nosso artigo recentemente publicado "'Pensiero debole"", diferença e alteridade: uma releitura". ${ }^{6}$ Tal obstinação de recorrência se justifica pelo simples fato de que tais temas essenciais se constituem, a rigor, na medula do que pretendemos seja a nossa produção propriamente dita na área da filosofia, e por isso a esses temas sempre retornamos.

\section{a) No princípio era a Diferença}

Não nos parece difícil constatar um fato histórico-filosófico de grande significação: o índice de incisividade e perenidade crítica de uma escola filosófica pode ser aquilatado, em boa medida, pela seriedade com que tal escola trata do tema da "diferença", aqui entendida inicialmente em sentido lato. Autores e escolas que trataram deste assunto como se fosse um conceito operativo entre outros, redutível a uma lógica privada ou a um conjunto de procedimentos intelectuais, tendem a ser esquecidos rapidamente quando do advento de modelos mais vigorosos de reflexão filosófica; autores e escolas que abordaram tal temática com extrema seriedade e cuidado (ou melhor, que fizeram de tal temática, de certo modo, o motor de suas construções intelectuais) - como é o caso paradigmático do pensamento kantiano ou da filosofia sistemática hegeliana - perduram muito além de sua mera circunscrição histórica, renascendo sempre pela força do real a que se vertem.

Por outro lado, haverá, na filosofia mais recente, uma palavra tão maltratada como "diferença"? Sua redescoberta como ponto de torção racional explícito levou, em muitos momentos, a uma verdadeira folclorização desse conceito. Seu poder filosoficamente crítico, levado a patamares inusitados justamente por Hegel, ${ }^{7}$ viu-se em muitos momentos do século XX - e não por culpa de seus detratores, mas primariamente de seus admiradores - reduzido a níveis de inofensividade inéditos, dolorosamente contrastantes com o que acontecia em outros campos da cultura. ${ }^{8}$ Todavia, a marca heideggeriana insuflou-se indelevelmente nos autores de estilo mais fenomenológico de escrita. A percepção posterior de que a différance derridiana inaugura uma nova chave interpretativa para o tema que corre pari passu com os temas da exterioridade e da alteridade em Levinas, essa percepção não é absolutamente de domínio comum. O resultado é conhecido: "diferença", termo mal-compreendido e maltratado, estandarte proclamado de um ou de muitos estilos filosóficos, não diz mais aos contemporâneos aquilo que parecia sugerir originalmente, antes de sua proclamação. A maldição do banal o atingiu.

\footnotetext{
In: Alceu. Revista de Comunicação, Cultura e Política, v. 7, p. 254-273.

Cf. nosso Sentidos do Infinito - a categoria "infinito" nas origens da racionalidade ocidental, dos présocráticos a Hegel, p. 87-114.

8 Para um estudo mais detalhado deste tema, cf. nosso já citado "O século XX e a desagregação da totalidade", bem como nossa "Introdução" a SOUZA, R. T., As fontes do humanismo latino - A condição humana no pensamento filosófico contemporâneo.
} 
Mas, não obstante, o pensamento ocidental se estrutura, desde os seus primórdios, exatamente em torno à questão da diferença. É em torno a esse núcleo referencial que os grandes problemas clássicos da filosofia, ou seja, o que conhecemos normalmente como raiz do pensamento ocidental logocentrado (o termo não tem aqui, absolutamente, conotação depreciativa, apenas constatativa) se articulam e amadurecem enquanto, exatamente, problemas fundamentais: particular versus universal, necessário versus contingente, finito versus infinito, sensível versus racional, alma versus corpo, chaos versus kosmos - as dualidades opostas são infindas e remetem, em última análise, sempre ao mesmo problema anterior que as gera: à questão da não-unidade - da diferença - da realidade com relação a si mesma. Houvesse tudo em tudo, e o resultado seria a onisciência e a dispensabilidade do pensar; mas é porque há desvãos, desencontros e desencaixes na estrutura do real (seja esta qual for, porque a concepção de realidade se articula justamente em torno a esses desencontros, desvãos e desencaixes), que o pensamento se gera, e se gera como urgência, urgência de índole cognoscenteclassificatória, e isso já desde sua mais remota origem, referida ao "desencontro" pré-original entre ser e pensar. Contrariamente ao senso comum filosófico, cumpre-nos ressaltar aqui com todas as letras: no início, não é o verbo Ser - muito menos a unidade -, mas os desencontros que o verbo Ser tenta de algum modo identificar, retraindo ao presente de (seu) indicativo verbal: o verdadeiro Leitmotiv do logos. Se "isso" fosse desde sempre apenas "isso" - $\{X=X\}$, uma afirmatividade absoluta, auto-identificante e finalmente tautológica -, não teríamos provavelmente filosofia alguma, pois a tautologia perfeita desaparece em si mesma e para si mesma inclusive enquanto problema, entendendo-se como identidade original e originante; ${ }^{9}$ mas é porque "isso" é também "aquilo", ou não é somente "isso", ou deve ser "aquilo", ou pode ser compreendido de outra forma, ou se constitui em instância de uma síntese maior - \{X não é Y $\}$ - que o pensamento cognoscente se põe em marcha em seu processo essencialmente identificante de forma que, ao fim e ao cabo, "isso" "se encontra", ainda que na órbita fechada de uma racionalidade particular, consigo mesmo. Uma série de funções do processo de identificação, do processo cognoscitivo, se unem nesta tarefa: a localização, a comparação, a nominalização, a determinação, enfim. Quando, ao final de minhas análises, promulgo que "o pinheiro é um vegetal", isso significa a culminância de um longo e árduo itinerário. Tive de "perceber" a realidade; destacar dali algo especial a ser "classificado"; destacar deste "algo" o seu "conceito" (ou

Não entraremos aqui na discussão de um outro complicador desta questão: uma vez afirmada a unidade absoluta na origem e que se desdobra logicamente em uma equação, toda diversidade lhe é posterior e subalterna e, portanto, rigorosamente dispensável, a não ser como combustível mental e real da tautologia. Estamos aqui não às voltas com uma lógica mais ou menos sofisticada de identificações e desidentificações, mas face a uma sutil expressão de violência, bem traduzida por Derrida, a partir da identificação $(\mathrm{x}=\mathrm{y})$, como um processo de equalização e subordinação violenta de x a y. Nesse sentido, não existe lógica, por mais formal que apareça, que não seja essencialmente onto-lógica, ou seja, expressão de afirmação do ser sobre o não-ser. Esta é a falácia de muitos modelos lógicos aparentemente vazios de conteúdo. 
mesmo "construí-lo"); tive de comparar esse "conceito" com semelhantes e dessemelhantes; "atribuir" a esse conceito um "nome"; e, finalmente, propor a identificação entre esse nome e o alvo de minhas atenções. Mas, a rigor, o processo é o desdobramento de uma fórmula mais simples. Inicia com um "o que é isso?" $\{X=?\}$; desdobra-se em "isso pertence à classe lógica dos vegetais" $\{X=Y\}$ e desemboca na nominalização onde se pretende que a essência ou o essencial do pinheiro seja dado, coincida com seu nome: "isso é um pinheiro", ou seja, "isso, que é identificado como sendo um pinheiro, é um pinheiro" $\{X=X\}$. O que aqui realmente nos interessa - o que esteve por trás e realmente sustenta todo esse procedimento - é um processo identificante. E esse processo identificante consiste justamente na tentativa de retirar da diferença seu caráter, exatamente, de "diferente" enquanto tal, transmutando-a em diferença lógica, ou seja, em uma espécie de combustível da máquina identificante do pensamento. E é interessante notar que tal dado é comum a todas as grandes lógicas ocidentais clássicas, sejam de índole formal, sejam de teor dialético. No primeiro campo, temos a articulação da variedade do mundo em torno a uma referência significante que lhe dá sentido: o verbo Ser, a presença do real em torno às definições da possibilidade de o real ser, exatamente, real. No segundo caso, a diferença - a negação - assume uma posição mais consistente, é levada pretensamente "mais a sério"; mas, pela sua própria dinâmica, a dialética não cessa, seguindo adiante na direção de uma Aufhebung ou sín-tese que, contendo embora a diferença, não a trata como tal, mas como momento dialético a ser ultrapassado no momento seguinte que é, de uma ou outra forma, re-identificante. Não podemos deixar aqui de apontar que a Dialética Negativa é uma tentativa extrema e refinadíssima de deter essa compulsão à identidade, este delírio totalizante, que afeta o cerne do movimento o qual leva a diferença ontologicamente a sério; ${ }^{10}$ sua grandeza consiste em permanecer ela mesma exatamente pela negação factual de sua estrutura lógica, se quisermos levar a sério o esforço adorniano. ${ }^{11}$

Assim, podemos propor tranqüilamente que a diferença é a questão propriamente dita do pensar; é sua condição, como é o impedimento de sua completação, pelo fato de ser, desde sempre, o seu Outro. A questão da diferença é a provocação a um processo de compreensão do "todo", ao mesmo tempo que bloqueia, por sua recorrência incômoda e indeclinável, qualquer invectiva de universalização totalizante. É por isso que o pensamento - e a filosofia, enquanto determinada forma de organização do pensamento - tem de se ver continuamente confrontado com o problema das origens, dos fundamentos, dos pressupostos, antes de se preocupar com as conseqüências e com os sistemas, mesmo sabendo que nunca chegará totalmente às origens, aos fundamentos e aos pressupostos. É por isso, também, que o pensar é uma tarefa infinita, uma arqueologia interminável, e tem

Cf. SOUZA, R. T. de. "Estética e restos da história" in: SOUZA, R. T., Totalidade \& Desagregação Sobre as fronteiras do pensamento e suas alternativas, Op. cit., p. 40-46.

${ }^{11}$ Cf. SOUZA, R. T., Razões plurais - itinerários da racionalidade ética no século XX - Adorno, Bergson, Derrida, Levinas, Rosenzweig, p. 93-126. 
de necessariamente reiniciar a cada momento: tal é explícito no filosofar ocidental, quando se percebe, por exemplo, que para além de suas diferenças de encaminhamento da questão, Parmênides e Heráclito, Platão e Aristóteles e tantos outros exemplos de aparentes opostos intelectuais pensavam, no fundo, o mesmo problema, que não era, a rigor, senão o problema do mesmo, ou seja, o problema do Ser: a solução da questão da diferença, como veremos adiante de forma mais detalhada. Para além de qualquer fabulação ou imaginação, antes de toda síntese e organização mental, dá-se a diferença: este fato é tão real aqui e agora, neste exato momento, como o foi para o primeiro pensador que percebeu sua nãocoincidência com o que não era ele, e entendeu, segundo sua cosmovisão particular, a necessidade de superar tal não-coincidência como condição ou realização do processo compreensivo do real enquanto tal. Superar a diferença é o ato fundante que se concebe, muito prematuramente, como movente do grande projeto do pensamento cognoscente, como a base da possibilidade de se pensar a própria condição de inteligibilidade do real.

Inicia-se, portanto, historicamente, o processo de "compreensão apropriativa" da diferença, ou seja, de sua integração a uma ordem maior de sentidos que compõe as diversas formas de avançar do pensamento que pretende conhecer. Tal não se dá por uma escolha consciente de algum gênio isolado, mas por um arranjo pré-original do que se considera implicitamente condição de todo conhecimento: identificar o conhecido consigo mesmo, chegar ao real desde dentro dele mesmo.

Constituir-se-á originalmente o corpo hegemônico da filosofia ocidental, em suas grandes linhas, por este viés? Provavelmente. As questões originais que a tradição nos lega, ainda que fragmentariamente, bem o sugerem; as partículas de poemas cosmológicos, as obscuridades e clarezas dos antigos, assumem essa tonalidade inquieta. Logo se propõem um antes e um além do visível; à sua procura se dedicam as mentes mais agudas. Caminha-se por sobre a inquietude do dado da diferença; mas essa inquietude é a base que, segundo a convergência das energias unificantes, é preciso superar; é necessário chegar à sabedoria, superar as aparências, abordar solidamente o existente, afrontar e vencer a insegurança das não-coincidências, do universo da multiplicidade.

Alguns passos são, porém, previamente necessários. Para os fins desta reflexão, basta-nos destacar três: a dualidade original ser/não-ser, a "espacialização" da temporalidade e a objetificação intelectual-neutralizante do dado que é alvo das energias filosóficas, ou seja, do que se apresenta como real ao intelecto cognoscente.

\section{b) O primeiro passo do processo de objetificação/ superação da diferença: sobre Ser e Não-ser}

A conseqüência da percepção de uma "situação original", na qual se ancora a possibilidade de o ser humano perceber a realidade com sentido, é que nada se pode perceber de "humano" que não esteja afetado por este "estar situado". Tal é válido também para as comunidades humanas grandes e pequenas, articuladas 
em coletividade de sentido, e que são, em realidade, pluralidade de mundos em íntima interpenetração. Compartilhamos assim a tese de que, antes que um povo ou conjunto de povos pense em expressar suas vivências originais em termos poéticos, literários ou filosóficos, estas não somente já existem desde há muito, como assentam sobre bases de difícil - ou, praticamente, impossível - intelecção por parte deles mesmos e para os pósteros. Ninguém - e aqui se inclui a totalidade das culturas - atinge a plenitude de seus pressupostos, ninguém capta o estertor original que dá origem à vida ou à inspiração prévia a toda expiração. Estes pressupostos são mais antigos que sua expressão, mais fundamentais que qualquer materialização ulterior, realidade prévia a toda realidade posterior, base possível de todo pensamento.

Qual seria, então, a cosmovisão geral ou posição originária que se expressa e se desdobra pela árdua via do logos ocidental? Trata-se de uma determinada instalação original no mundo, de uma determinada concepção de realidade prévia a todas as outras, e que as outras, suas herdeiras, hão de tentar compreender e criticar. Essa realidade toma forma, por vez primeira, na articulação de uma determinada linguagem como expressão de racionalidade.

Essa posição originária se traduz pela intenção de penetração unívoca, racional, na realidade. A linguagem grega, bela tradução desta origem no passado e inspiradora de inúmeras linguagens futuras, tem no verbo Ser sua essência mais profunda, o essencial de sua autocompreensão. No verbo Ser cruzam-se todos os sentidos e suas possibilidades, estabelece-se de forma definitiva a forma equacional já examinada $\{X=Y\}$, isto é aquilo, o cavalo é um animal, o homem é um animal racional e político. Antes de ser racional ou político, o homem é alguma coisa, e antes de ser alguma coisa "específica", tem de já "ser" alguma coisa prévia à própria especificação, por habitar desde sempre o verbo "ser" - nisto coincidem os mais antigos metafísicos com os mais recentes filósofos da Fundamentalontologie. É na igualdade, na equalização do diferente, no processo dinâmico desta equalização de uma vez para sempre, que repousa a segurança do logos. É ali que o logos encontra sua origem, como Ulisses, metáfora logocêntrica por excelência, reencontrou sua pátria. Este é o parentesco original de todo realismo com todo o idealismo: um não pode conceber-se, em última análise, sem o outro. A intimidade mais profunda da lógica grega, determinativa, tem seu peso, seu sentido mais próprio, na conexão dos particulares: tudo é importante na equação, mas ainda mais importante é a marca, o sinal de equalização traduzidos pelo verbo Ser, pois ali repousa, em última análise, o peso da realidade para o logos. A lógica grega é enunciativa, vive de seus enunciados, pais de toda concepção de ciência até algumas reviravoltas contemporâneas ainda não bem compreendidas nem assimiladas pela ortodoxia bem-pensante. Sua preocupação pela precisão é a preocupação por sua vocação maior.

A linguagem grega enunciativa pressupõe assim, a bem até mesmo de sua autocompreensão, uma espécie de solidão ou solipsismo original, a pretensão intelectual a uma univocidade perfeita de sentido, atualizada ou em potência. A razão, como expressará a mentalidade moderna, tem de ser uma só; pois o contrá- 
rio seria compatível com a multiplicidade de sentidos, e o sentido está dado, de uma vez para sempre, na expressão da igualdade "equacional", no verbo Ser. Algo é, ou não é: tertium non datur - eis a regra original, da qual dependem todas as outras da lógica de origem grega, inclusive, como já sugerimos, a lógica dialética. O enunciado da razão como razão é a equação do verbo Ser: a igualdade redentora afasta da razão o perigo do diferente dela, ou seja, do tempo e da multiplicidade real.

Eis, portanto, um primeiro passo fundamental e grandioso no processo de domesticação da diferença: sua subordinação a uma determinada lógica e linguagem que, ao se propor como única possibilidade (ou como "verdadeira" possibilidade, o que, na órbita de sentido de uma verdade solitária, vem a ser categorias mutuamente conversíveis) de abordagem do real, transborda ontologicamente de si mesma e determina também o não-ser, ou seja, o irreal. É nisso que, como já sugerimos, Parmênides e Heráclito, quase sempre apresentados como "adversários", concordam definitivamente, e concordam ainda antes que essa inspiração original possa se conformar em qualquer tipo de organização lógica. E é nisso também que concordará a imensa maioria dos múltiplos pares digladiantes da história da filosofia greco-ocidental, tais como resgatados pelo senso comum histórico-filosófico.

\section{c) O segundo passo na superação da diferença: a espacialização da temporalidade}

Porém, de nada adiantariam tais esforços lógicos se, no âmbito de um universo mental, a temporalidade simplesmente continuasse a ocorrer pelas bordas dos sistemas lógicos, por mais sofisticados que estes sejam. E a temporalidade, expressão da diferença, dá-se originalmente como fundamento de toda inquietação filosófica, ainda que sob nomes os mais diversos: finitude, contingência, acidente, mundo empírico, etc. - e, até mesmo, exatamente, diferença, como em Rosenzweig. Há, portanto, com relação à temporalidade, de neutralizá-la; caso contrário, cada categoria lógica teria de ser reinventada a cada passo, para repor na ordem plenamente inteligível da realidade do ser aquilo que o tempo acaba de corroer. A univocidade do conceito estaria perdida, e cada generalização, indução ou dedução estaria condenada a priori ao fracasso.

Essa neutralização, porém, não pode padecer de ingenuidade, pois o poder desagregador da temporalidade real é imenso. Para tratar desta questão são, portanto, mobilizadas grandiosas potências racionais; e uma das primeiras soluções, e das mais clássicas, procura equiparar a não-visibilidade do tempo à visibilidade do espaço, "logicizando" espacialmente a primeira: quando se pensa em termos de se constituir o tempo na medida do movimento, pensa-se exatamente em subordinar o que não se dá no espaço enquanto categoria àquilo que se dá neste espaço; e, portanto, avança-se decididamente no controle do imponderável desagregante, manietando-o à controlabilidade de uma rede de conceitos. E pode-se perceber que, ao longo de mais de dois milênios de pensamento filosófico, esta é uma das 
questões mais recorrentes, pelo menos até a segunda metade do século XIX: como transformar o tempo em intemporalidade, para neutralizá-lo em seus efeitos corrosivos das certezas conceptuais? Esta é a demarcação do início do estilo contemporâneo de filosofar: quando a percepção de que a temporalidade "existe" é inelutável na raiz do próprio pensar, e a questão acima se dilui no imponderável e na inquietude da contemporaneidade, esta crise na qual ainda vivemos. ${ }^{12}$

Assim, em termos práticos, o tempo que penetra até mesmo a equação do verbo Ser é congelado no verbo Ser. A rigor, não existem propriamente o passado e o futuro, exceto como antevisão e celebração da conquista do Ser. No presente do "é", o passado e o futuro deixam de assustar: encontraram-se a si mesmos, neutralizando-se mutuamente. Não necessitam colocar-se como alternativas prospectivas ou retrospectivas de realidade, pois a realidade está já resolvida na fixação de alguma espécie de presente eterno ao qual o logos, a iluminação, tem acesso completo. Na construção pré-socrática, na platônica com suas "idealidades realistas" ou na aristotélica com seu "empirismo" que deriva em metafísica, e em todas as suas derivações, inclusive nos processos modernos de subjetivação propedêutica ou radical (inclusive em sua inversão em "objetivação" radical do idealismo absoluto) - em cada instância, a preocupação "determinativa" é, em análise derradeira, a mesma. ${ }^{13}$

Mas o que "determina" praticamente essa linguagem ao mundo que a utiliza? Desde a perspectiva da fixação do correr do tempo no espaço próprio do presente, são perceptíveis ao menos duas grandes características, que se apresentam também como dimensões de interpretação:

A) Em primeiro lugar, uma espécie de explícita dualidade definidora estabelecida na antropologia, já antes sugerida em termos categoriais, que não se opõe, mas antes remete, no fundo, a um monismo radical implícito: o monismo do Ser. A realidade está cindida em dois níveis de difícil aproximação: o empírico, a doxa, o corruptível, o impuro, o plural, o temporal, e a dimensão da felicidade ideal, a episteme, racional, meta-empírica, incorruptível, transcendental, "para além das aparências", pura, singular, atemporal. Mas essa cisão também pertence ao mundo das aparências, já que, em verdade, somente a realidade atemporal é, conforme vimos, legitimamente real para essa concepção de realidade. A vita activa, com seus percalços e inconstâncias, não participa da realidade plena da contemplação atemporal das essências. O Bem residiria na atemporalidade da Totalidade de sentido do verbo Ser, "presente eterno", totalidade esta que se encontrou consigo mesma: eis o mote de fundo, "inconsciente", a anterioridade da determinação de realidade do mundo.

2 Cf. SOUZA, R. T. de, Totalidade \& Desagregação. Sobre as fronteiras do pensamento e suas alternativas, p. 15-29.

${ }^{13}$ Cf. SOUZA, R. T. de, Sentidos do Infinito - a categoria "infinito" nas origens da racionalidade ocidental, dos pré-socráticos a Hegel. 
B) Em segundo lugar, e como conseqüência da concepção de atemporalidade atribuída à realidade plena, percebe-se a radical anti-historicidade que habita esta concepção de verdadeira realidade. A história do desdobramento do logos, apesar das aparências em contrário, é uma anti-história, - uma espécie de história "endógena" - porque é afinal de contas um encontro consigo mesmo. Mais uma vez, Ulisses nos esclarece isso. Sua aventura tem como ultima ratio a finalidade do retorno à sua pátria, a si mesmo. A mutabilidade que caracteriza a história aberta - o tempo como condição de efetivação da realidade, a possibilidade do novo - é, na verdade, um desembocadouro do incontrolável, e, portanto, um escândalo para qualquer constelação bem-arranjada de conceitos. É nesse sentido que a temporalidade é a expressão última e mais aguda da negatividade enquanto tal, e dela não se pode prescindir em qualquer crítica à Totalidade ontológica.

A anti-historicidade se expressa especialmente na redução do imprevisível à inofensibilidade. A cosmovisão original anti-histórica tenderá mais tarde, em seus desdobramentos modernos, a subsumir o particular, o propriamente concreto da história, no universal e abstrato do Espírito e da Totalidade - tarefa empreendida por Hegel com tanto brilhantismo, e que dará a Benjamin, na intuição do movimento contrário, oportunidade para tanto trabalho. ${ }^{14}$

\section{d) O terceiro passo na superação da diferença: a objetificação intelectual-neutralizante do real}

Ainda um terceiro elemento é fundamental no processo de inofensibilização da diferença: trata-se da neutralização do real através do crivo neutralizante do objetivismo intelectual, ao qual chamamos, neste contexto, de "objetificação". E não falamos, aqui, de um "objetivismo" que meramente se oponha a um "subjetivismo", ou de algum tipo de positivismo ingênuo, mas de algo mais profundo, que remete às origens do fluxo identificante que tem como resultado a articulação lógica intemporal da realidade à qual já fizemos referência. E esta é a dimensão que, em nossa discussão, relacionando o tema da ética com o dos animais, assume uma importância singular.

Em poucas palavras, o que aqui chamamos de "objetificação" se constitui, exatamente, no conjunto dos processos maiores, chanceladores da legitimação dos processos parciais aos quais denominamos anteriormente "autopostulação da identidade" e "espacialização da temporalidade". Ou seja: a objetificação é a forma de emprestar legitimidade às lógicas da postulação absoluta do ser enquanto realidade e da temporalidade enquanto não mais que "pré-realidade", lógicas estas que, como vimos, têm como impulso inicial e objetivo final despojar a diferença de seus elementos desagregantes originais: inofensibilizar a alteridade. As variadas formas de como tal processo se tem dado ao longo da história do pensamento desembocam todas neste mesmo desaguadouro da pretensa naturalidade, que faz com que, em cada época, se tenham categorias-chaves para entender e legitimar

Cf. BENJAMIN, Walter. "Teses sobre o conceito de história". In: BENJAMIN, W. Obras Escolhidas. 
cada passo desse grande processo de "des-diferenciação", categorias estas tratadas geralmente como sagradas ou intocáveis. É apenas quando um grande quadro cultural entra em crise que essa sacralidade é posta em dúvida; e, imediatamente, a inteligência guardiã do grande impulso neutralizante localiza uma substituta à altura, no campo das ciências ou dos grandes sistemas políticos e intelectuais. O grande horror da consciência ocidental é se ver às voltas com a realidade sem as chaves compreensivas que a própria cultura recria constantemente. É assim, por exemplo, com a categoria de "infinito"; enquanto tal pensamento trazia em seu bojo um poder de inquietação incontrolável, se lhe tinha repugnância - os gregos, de modo geral, pensavam desde o ponto de vista da ordem, do "cosmo", enquanto o ilimitado, o ápeiron, permanecia como uma instância de escândalo intelectual. ${ }^{15}$ Foi apenas bem mais tarde, nos inícios da modernidade, que se pôde afirmar a infinitude do universo sem temor do descontrole "caótico" (dos antigos) ou da alteridade absoluta divina (dos medievais); e é exatamente este o momento em que inicia propriamente a modernidade.

Assim, a "objetificação-neutralização" é o próprio exercício da inteligência, enquanto este exercício visa a preservação de sua segurança original: sua referencialidade em torno ao núcleo auto e hetero-identificante. É por isso que se tem considerado tradicionalmente a inteligência como avessa a condicionalidades, que atenuam sua agudeza identificante.

\section{Da neutralização da diferença à dignidade da alteridade}

\section{a) Pó e cinzas}

\section{"Após ela (a filosofia) haver recolhido tudo em si... o ser humano descobre subitamente que ele... ainda está aqui... Eu, pó e cinzas, eu ainda estou aqui" Franz ROSENZWEIG ${ }^{16}$}

Três "passos", na verdade dimensões interpenetrantes de um mesmo grande "movimento", foram acima sugeridos: a "definição definitiva" da impossibilidade do diferente do ser, ou melhor, do diferente que ser; a obsessão pela detenção da temporalidade incontrolável e sua incorporação em uma espacialidade cósmica ou lógica "controlável"; e as formas pelas quais tais objetivos são atingidos, ou seja, os modos de "chancela neutralizante" que se apõem a tais conquistas e que pretendem, com isso, a evitação da recorrência da situação mais original de "caos", quando a diferença era real e não apenas lógica e metodológica. Com isso, toda realidade nada mais é do que uma questão de "conhecimento", e conhecimento organizado em torno à procura daquilo que temos chamado de "verdade solitária",

15 Cf. nosso Sentidos do Infinito - a categoria "infinito" nas origens da racionalidade ocidental, dos présocráticos a Hegel.

16 Kleinere Schriften..., p. 359. 
a correlação entre um intelecto cognoscente e um "objeto" de sua atenção cognitiva.

Sintetizemos, portanto, o até aqui exposto:

1) O modelo ocidental de pensamento, sua dinâmica, é já ex origine um grande arco de poderosa afirmatividade, provocado pelo fato originante de que, antes de tudo, dá-se a diferença: todo pensamento, toda filosofia, toda ciência têm aí sua origem mais remota. O logos tem aí seu único e real problema, o problema em relação ao qual todos os outros assumem uma dimensão secundária, e a inteligência como que parte imediatamente para a conquista dessa terra (ainda) incógnita.

2) Tal se dá, ao longo do tempo, pela paulatina domesticação daqueles elementos que podem introduzir, no grande corpo do conhecimento, a sombra da dúvida: o extrapolar de categorias - "não-ser"; o extrapolar da controlabilidade - o tempo que passa e desagrega o todo; e o extrapolar da "inteligibilidade" normal algo que, atraindo as energias do conhecimento, dá-se por fora ou para além das possibilidades puras do conhecimento. ${ }^{17}$

As últimas energias positivadas desse espírito identificante se dão, na forma exposta, à época dos grandes sistemas totalizantes do pensamento - até pelo menos meados do século XIX. É a partir daí que um grande processo de corrosão interna tem origem. ${ }^{18}$ E se o logos se traduz em habilidade extrema na dimensão que identifica as diferenças "externas", tal não se dá no que se refere aos grandes problemas internos da cultura na qual se move; e o problema que então se propõe é de tal ordem que a totalidade de mecanismos legitimadores da positividade da procura é colocada em questão. A partir da segunda metade do século XIX, pelo menos, o grande problema já se conforma inequivocamente: dá-se a percepção de que, a um Eu claro e distinto, contrapõem-se os "eus" sombrios e indistintos, atuantes do psiquismo "subterrâneo"; a uma compreensão essencialista e formal da realidade, contrapõe-se uma visão "evolutiva", onde o tempo, por tantos séculos recalcado, faz sua reentrada triunfal; a uma matemática "natural", a uma geometria intuitiva, contrapõem-se geometrias "artificiais", que nem por isso têm menos validade matemática do que a euclidiana; a uma música tonal, e, portanto, formalmente controlável a priori, contrapõe-se o princípio de desagregação da tonalidade, que conduzirá fatalmente a sendas desconhecidas; a uma arte figurativa "realista", contrapõem-se uma multiplicidade de estilos, que criam realidades diferentes daquelas retratadas pela tradição; a uma literatura formalmente bem comportada, propõe-se uma construção literária infinitamente variável; a uma ciência bem-organizada, contrapõe-se uma "ciência" essencialmente indetermina-

17 É importante que se perceba que nos é perfeitamente claro que esta linha simplificada de argumentacão não subsume as infinitas variantes que, a cada passo, se estabelecem em contraponto a esta grande dinâmica; mas o que se quer destacar é que a grande linha determinante da civilização ocidental é a acima exposta, para a qual, justamente, as variações nada mais são do que desvios necessitados de correção.

${ }^{18}$ Cf. SOUZA, R. T. de. Totalidade \& Desagregação. Sobre as fronteiras do pensamento e suas alternativas, p. 15-29. 
da. Tudo parece fugir ao controle: espaço para o surgimento do grande Medo ${ }^{19}$. Penetra-se, de corpo e alma, na imensa crise civilizatória na qual estamos mergulhados. Na esteira de Rosenzweig, somos obrigados a constatar: filosofias surgiram, filosofias desapareceram e nós, "pó e cinzas", (ainda) estamos aqui. Após séculos de otimismo e de pretensa obviedade do sentido, a questão do sentido dos sentidos pressupostos pela inteligência do real se re-propõe com inusitada violência, uma violência que é uma contrapartida à altura da violência identificante que habita a raiz da racionalidade solitária, o coração do logos em sua dimensão ancestral.

\section{b) Crises, arqueologias e novas descobertas: finitude e temporalidade ${ }^{20}$}

As formas de resistir a tal embate são variadas; desde o conservadorismo filosoficamente inócuo, porém culturalmente impiedoso, até arqueologias radicais em busca da melhor circunscrição da questão do sentido conforme acima sugerida, e desde uma vigorosa retrovisão arcaizante até prospectivas inusitadas no encalço do Novo. O fato é que nenhum pensador digno deste nome, no século XX, pode pensar ignorando esta situação de crise, de colapso de uma Totalidade de sentido. A temporalidade faz sua reentrada triunfal no campo do possível, e no século XX já não é possível ignorá-la: esta não-ignorância é o proprium dos discursos filosóficos contemporâneos.

Com o Tempo, ressurge a Diferença: com o colapso do Conceito identificante, que retira da alteridade apenas e tão somente aquilo que é intelectualmente compreensível, reassume seu lugar a questão da Alteridade real enquanto dimensão que não pode ser, simplesmente, representada ou mesmo "intelecualizada", mas remete às profundezas de uma "indeterminação" original, onde nada é suficientemente "claro", porque a clareza não é a questão original, mas, exatamente, é a diferença que é a questão original.

A percepção da radicalidade desse problema não escapa a alguns contados pensadores extremamente agudos: todos sabem que precisam defrontar seriamente com este problema. Investem na dilatação da estrutura original de compreensão do real. Filósofos os mais diversos concentram o melhor de suas energias em torno a esse problema. Suas soluções variadas contemplam paradoxalmente inquietações de origem bastante semelhantes, que são propriamente as inquietações filosóficas da contemporaneidade. ${ }^{21}$

Conhecemos a história da filosofia contemporânea: a reproposição da questão original da temporalidade é compreendida inicialmente como finitude ou mesmo como náusea, assim como a emergência da alteridade original é compreendida

9 Cf. nosso Metamorfose e Extinção - Sobre Kafka e a patologia do tempo.

${ }^{20}$ Cf., a respeito deste tema geral, nossos Fontes do humanismo latino - A condição humana no pensamento filosófico moderno e contemporâneo e Razões plurais - itinerários da racionalidade ética no século XX.

21 Defendemos esta posição compreensiva especialmente em nossos livros Totalidade \& Desagregação... e Sujeito, Ética e História... . 
como negatividade; ${ }^{22}$ nada impede que se consubstancie um novo terreno propício a novas caminhadas e novas descobertas.

Na particularidade da fenomenologia e de suas derivações, Husserl "resolve" a questão da intencionalidade intelectual, reabrindo o campo da imponderabilidade do real; e, como vimos, Heidegger supera a tradicional proposição lógica da diferença "invertendo-a" e "positivando-a" enquanto diferença ontológica. ${ }^{23}$ Está refeito um terreno filosófico que se presta a uma re-aproximação filosófica da questão da diferença.

\section{c) A reafirmação da dignidade da Alteridade}

Superamos, porém, a etapas das ingenuidades bem-intencionadas: se há uma lição que dois mil e quinhentos anos de história e de filosofia bem nos ensinam, é a de que, pela via do intelecto iluminante, podemos ir até aos limites do iluminado pelo intelecto, e não mais além. ${ }^{24}$ Se isto é o que concebemos como sendo a totalidade das possibilidades de pensar e do conceber, então chegamos realmente aos limites da filosofia e ao fim da história; se, porém, ao estilo da primeira frase da Negative Dialektik de Adorno, percebemos aí uma unilateralidade que envia, por sua vez, a uma estranha e provocativa obscuridade, a uma "má consciência", ${ }^{25}$ a uma outra história, a um outro tempo que o tempo da sincronia, então estamos talvez preparados para ousar enfrentar o receio do desencontro, do paradoxo, do desvão, do fulcro que "incide" na construção do corpo dos conceitos. Desde a cinza da era das catástrofes, ${ }^{26}$ estaremos, em outros termos, finalmente preparados para retornar à questão original: a questão do sentido do real. Porém, não o faremos apenas com as armas da tradição, mas com tudo aquilo que a linha hegemônica da tradição nunca ouviu nem soube identificar.

Não reiniciamos, portanto, nosso itinerário à maneira de identificação de representações, mas auscultando os vestígios do irrepresentável; não decaímos em irracionalidades desesperadas ou apocalípticas, mas também não identificamos a racionalidade com a Razão onipotente. Não ignoramos que, do Outro, somente captamos o que se dá à nossa representação, e que sua alteridade se refugia para além da própria estrutura de cognoscibilidade e de manipulação do logos ${ }^{27}$ - e

22 Cf. nosso ensaio "Sartre e a ambigüidade da percepção", in: SOUZA, R. T. de, Totalidade \& desagregação..., p. 81-100.

${ }^{23}$ Cf. SOUZA, R. T. Husserl e Heidegger - motivações e arqueo-logias". In: SOUZA, R. T. de, O tempo e a Máquina do Tempo - Estudos de Filosofia e Pós-modernidade.

${ }^{24}$ Cf. SOUZA, R. T. "Das neue Denken und die Ermöglichung des Friedens - Franz Rosenzweig und Emmanuel Levinas im Zentrum der Ereignisse des 20. Jahrhunderts", p. 590 ss; "Da lógica do sentido ao sentido da lógica: Levinas encontra Platão", entre outros.

25 Cf. LEVINAS, Emmanuel. "A consciência não-intencional" in: LEVINAS, E. Entre nós - Ensaios sobre a alteridade, Petrópolis: Vozes, 1998.

${ }^{26}$ Cf. SELIGMANN-SILVA, Márcio. "A história como trauma", in: NESTROWSKY, Arthur - SELIGMANN-SILVA, Márcio (Orgs.), Catástrofe e Representação, p. 73-98.

${ }^{27}$ Cf. nosso ensaio "O delírio da solidão - o assassinato e o fracasso original". In: SOUZA, R. T. de, Sentido e Alteridade - Dez ensaios sobre o pensamento de Emmanuel Levinas. 
também não desprezamos o fato de que, sem esses cuidados, nos tautologizamos em uma Totalidade autofágica, beco sem saída de qualquer lógica do absoluto.

Mas, antes e acima de tudo, não hipotecamos nossa confiança a alguma estrutura onde o tempo se dissolve em algo categorial ou logicamente "maior" do que ele, tal como o Ser, mas articulamos a possibilidade de compreensão do real justamente à temporalidade real que se dá apesar de nós, do Ser e de nossa imensa capacidade sintetizante. Assim, desarticulamos a equação congelada em torno ao presente do indicativo de ser, perguntando simplesmente pelo sentido de ser; sentido que é outro que ser e que ser algum re-presenta ou pretenda esgotá-lo sem o violentar, uma vez que não é questão de ser ou não-ser, mas se sugere exatamente na diferença entre esses e quaisquer outros pares de conceitos. Dá-se a pluralidade de origem, ${ }^{28}$ e procurar o sentido do real significa, exatamente: construir a relação entre, no mínimo, dois diferentes - no famoso dizer de Levinas, "a ética é a ótica" primigênia, e a origem de todo o sentido, ou seja, a própria possibilidade de pensá-lo. O sentido do estabelecimento da ética como filosofia primeira não é mais do que isso: construir a compreensão de que o mundo, a terra, o universo se dão como um imenso "palco", no qual se deve desenrolar um drama ético enquanto fundamento da realidade e teoria pré-original de todo conhecimento possível. ${ }^{29}$ Muito provavelmente é essa a racionalidade original da existência humana, e não a exploração obsessiva de quarks e de quasars e galáxias distantes. Assim, se é verdade que "...A diferença entre o velho e o novo pensamento expressa-se... na necessidade do Outro e, o que dá no mesmo, no levar a sério o tempo", ${ }^{30}$ então a crise civilizatória em que nos encontramos nada tem de misterioso, nem em sua origem, nem em seu desenvolvimento; trata-se, em suma, das imensas conseqüências da pertinaz fidelidade a uma muito bem determinada lógica de princípios, que se propôs pensar e resolver o mundo desde a dimensão da identidade e da identificação. Grandes conquistas daí advieram; mas também daí provêm os imensos impasses em que nos encontramos. O seqüestro do "infinito" no presente, transformando a terra em um pretenso almoxarifado inesgotável e em um gigantesco depósito de lixo; a idéia suicida de que, de tanto rodar em torno a si mesmo, o frenetismo tresloucado acabará por se encontrar com suas razões; os automatismos e neutralizações bem pensantes, a violência e exploração desmedidas que habitam todos os níveis de realidade - tudo reenvia a um vício de origem: a obsessão solitária por uma "verdade solitária", a do tautológico e idêntico a si mesmo.

28 Cf. nosso Existência em Decisão - uma introdução ao pensamento de Franz Rosenzweig.

Ao contrário do que supõem certos hermeneutas de primeira hora, postular a ética como filosofia primeira não significa "abandonar" a ontologia, tarefa provavelmente impossível e absolutamente desnecessária; mas, antes, questionar construtivamente o sentido da espessura ontológica do real e o monismo auto-referente e neutralizante nos quais a maior parte das grandes filosofias têm depositado o melhor de suas esperanças.

ROSENZWEIG, Franz. Zweistromland, p. 387. 


\section{$4 \quad$ A alteridade dos animais}

Chegamos assim ao término de nossa breve incursão pela história do logos identificante, e podemos retornar agora à questão central que aqui nos interessa. Quem têm sido os animais ao longo da história do poder humano? Podemos iniciar caracterizando o que, por efeito dos impulsos de conquista humanos, de seu ímpeto no sentido de tentar "transformar o universo em um gigantesco campo de caça", ${ }^{31}$ os animais não têm podido ser: co-autores da sustentabilidade éticoecológica do planeta, ou seja, "outros". Máquinas vivas, alvos fáceis da vontade de destruição racional, objetos de exploração de todos os tipos, de tortura, de decoração e uso, sem falar em alimento sempre à mão, os animais experimentaram desde sempre todo tipo concebível de violência humana. Incapazes de argumentar senão com sua existência nua, expostos a todas as agruras por existirem sem poderem se contrapor a seres empenhados não apenas em reduzir obsessivamente a existência da realidade externa a uma função sua, mas em determinar absolutamente o valor de realidade do Outro que si mesmo exclusivamente a partir de categorias destiladas por seu próprio cérebro, algo mais desenvolvido em suas funções cognitivas, os animais não-humanos ocuparam sempre o lugar de alvo predileto de uso violento-objetificador da vida pelos animais humanos. Se é verdade que em todos os níveis da vida, da relação ser humano-natureza, evidenciou-se uma contínua disposição de transformação da natureza para fins poucos sustentáveis - situação que ninguém hoje ignora exatamente pelas reações da própria natureza como um todo, por exemplo, na questão do aquecimento global , é ainda mais verdade que em relação aos seres animados, e especificamente aos animais superiores, uma tal violência contínua cultivou e deu à luz os piores frutos da mania objetificante do homo sapiens. É uma questão de justiça histórica, e de justiça para com os vencidos em estilo benjaminiano e derridiano, lembrar que, até não muito tempo atrás, filósofos subiam a cátedras para explicar que as expressões de dor de animais vivissecados e torturados não eram de dor, mas reações maquínicas de uma máquina, já que aos animais faltaria a razão - talvez a razão de que se serviam tais filósofos para destilarem tais argumentos.

Todos esses fatos nos ajudam a perceber de forma cabal que, se é verdade que a crise que ora vivenciamos tem proporções inusitadas - e tudo leva a crer que tal se apresenta mais e mais como límpida verdade, como se pode observar pelas exigências que a natureza como um todo faz à ação humana, ultimato cuja alternativa é o extermínio dessa doença - o homem - que grassa sobre a pele da terra, como diria um Nietzsche ${ }^{32}$ - então é hora que se perceba finalmente, como já se sugeriu bem ao início do texto, que a categoria filosófica realmente adequada para conceber a existência dos animais é a Alteridade. Como toda realidade - não apenas a realidade humana - também os animais estão infinitamente além da

ADORNO, T. - HORKHEIMER, M. Dialektik der Aufklärung, Frankfurt a. M., 1984, p. 285.

Cf. SOUZA, R. T. de. "Ética e Ambiente. Por uma nova ética ambiental". 
capacidade de representação que deles se tenha, e o ônus da objetificação é exclusivamente de quem objetifica. ${ }^{33}$

Assim, a frase de Adorno, epígrafe deste texto, assume ainda um novo sentido: repositório de Alteridade desconsiderada pelos grandes tratados, os animais olham-nos desde o fundo da existência mesma, particular e não-intercambiável, totalmente singular por mais que sejam multidão, irredutível a generalidades ou ontologias gerais. Sua vida fala de outro modo que meramente existindo: chamanos a atenção, de modo pertinaz e infinitamente repetível, para a banalidade dos assassinatos, cometidos em série ou não, que têm, além de objetivos pragmáticos, objetivos crípticos de anular outras modalidades de existência, e evidenciam de modo definitivo os limites da capacidade representacional do intelecto identificante. ${ }^{34}$ Pois, ao contrário do que diz Levinas, também os animais podem ser assassinados (e não meramente "mortos"), e não apenas os homens, e o são tanto pelo menos tanto quanto os homens o são.

Concluamos, portanto: está mais do que na hora de nos despirmos de nossos preconceitos antropomórficos e entendermos finalmente que a percepção ética da Alteridade dos animais não é uma veleidade intelectual, ou um capricho contemporâneo, mas - além de um imperativo ético radical ${ }^{35}$ - uma questão de sobrevivência, e sobrevivência não apenas dos animais não-humanos, mas muito especificamente do único animal sobre o qual recairá a responsabilidade do fracasso absoluto, se a antevisão da catástrofe ético-ecológica que se insinua nas consciências lúcidas se realizar.

\section{Referências}

ADORNO, Theodor. Palavras e sinais - modelos críticos II, Petrópolis: Vozes, 1995. Minima moralia, São Paulo: Ática, 1993.

. Notas de Literatura I, São Paulo: Duas Cidades; Ed. 34, 2003.

Ästhetische Theorie, Frankfurt a. M., Suhrkamp (Teoria estética, São Paulo, Martins Fontes).

Negative Dialektik, Frankfurt a. M., Suhrkamp.

Prismas, São Paulo: Ática, 1998

ADORNO, T. - HORKHEIMER, M. Dialektik der Aufklärung, Frankfurt a. M., Suhrkamp, 1984.

AGAMBEN, Giorgio. Estado de Exceção, São Paulo: Ed. Boitempo, 2004.

BENJAMIN, W. Obras Escolhidas, São Paulo: Brasiliense, 1985.

DERRIDA, J. Adeus a Emmanuel Levinas, São Paulo: Perspectiva, 2004. Da hospitalidade, São Paulo: Escuta, 2003.

. Margens da filosofia, Campinas: Papirus, 1991.

A escritura e a diferença, São Paulo: Perspectiva, 1971

${ }^{33}$ Cf. nosso Sujeito, Ética e História - Levinas, o traumatismo infinito e a crítica da filosofia ocidental, (última parte).

${ }^{34}$ Cf. SOUZA, R. T. de. "O delírio da solidão: o assassinato e o fracasso original". In: SOUZA, R. T. de. Sentido e Alteridade - Dez ensaios sobre o pensamento de Emmanuel Levinas, p. 23-43.

35 Cf. nosso Ética como fundamento - uma introdução à ética contemporânea, p. 19-51, onde argumentamos de forma indireta no sentido do aqui proposto. 
O animal que logo sou, São Paulo: UNESP, 2002.

DERRIDA, J. - ROUDINESCO, E., De que amanhã..., Rio de Janeiro: Jorge Zahar, 2004.

FLICKINGER, Hans-Georg. "O fundamento ético da hermenêutica contemporânea". In: Veritas Revista de Filosofia, junho/2003.

KIPPER, Délio J. (Org.), Ética, teoria e prática: uma visão multidisciplinar, Porto Alegre: EDIPUCRS, 2006.

JÄGER, Lorenz. Adorno - Eine politische Biographie, München, Deutsche Verlags-Anstalt, 2003.

LEVINAS, Emmanuel. Totalité et Infini, Den Haag: Martinus Nijhoff, 1961.

. Autrement qu'être ou au-delà de l'essence, Den Haag: Martinus Nijhoff, 1974.

Entre Nós - Ensaios sobre a Alteridade, Petrópolis: Vozes, 1997.

. Humanismo do Outro homem, Petrópolis: Vozes, 1995.

NESTROWSKY, Arthur - SELIGMANN-SILVA, Márcio (Orgs.), Catástrofe e Representação, São Paulo: Escuta, 2000.

NACONECY, Carlos M. Ética e animais - um guia de argumentação filosófica, Porto Alegre: EDIPUCRS, 2006.

PELIZZOLI, Marcelo. A emergência do paradigma ecológico, Petrópolis: Vozes, 1999.

ROSENZWEIG, Franz. Das Büchlein des gesunden und kranken Menschenverstandes, Frankfurt am Main, 1992

Zweistromland - Kleinere Schriften zu Glauben und Denken (Gesammelte Schriften III), Dordrecht/Boston/Lancaster, Martinus Nijhoff Publishers, 1984.

SCHMIED-KOWARZIK, Práxis e Responsabilidade, Porto Alegre: EDIPUCRS, 2002.

SINGER, Peter. Libertação animal. Porto Alegre: Lugano, 2004.

SOUZA, Ricardo Timm de. Totalidade \& Desagregação. Sobre as fronteiras do pensamento e suas alternativas, Porto Alegre: EDIPUCRS, 1996.

- O tempo e a Máquina do Tempo - Estudos de Filosofia e Pós-modernidade, Porto Alegre: EDIPUCRS, 1998.

Existência em Decisão - uma introdução ao pensamento de Franz Rosenzweig, São Paulo: Perspectiva, 1999

Sujeito, Ética e História - Levinas, o traumatismo infinito e a crítica da filosofia ocidental, Porto Alegre: EDIPUCRS, 1999.

Sentido e Alteridade - Dez ensaios sobre o pensamento de Emmanuel Levinas, Porto Alegre: EDIPUCRS, 2000.

. Sobre a construção do sentido - o pensar e o agir entre a vida e a filosofia, São Paulo: Perspectiva, 2003

Fontes do humanismo latino - A condição humana no pensamento filosófico moderno e contemporâneo, Porto Alegre: EDIPUCRS, 2004.

Ética como fundamento - uma introdução à ética contemporânea, São Leopoldo: Editora Nova Harmonia, 2004

2004

Razões plurais - itinerários da racionalidade ética no século XX, Porto Alegre: EDIPUCRS,

. Metamorfose e Extinção - sobre Kafka e a patologia do tempo, Caxias do Sul: EDUCS, 2000.

Ainda além do medo - filosofia e antropologia do preconceito, Porto Alegre: DaCasaPalmarinca, 2002

. Sentidos do Infinito - a categoria "infinito" nas origens da racionalidade ocidental, dos présocráticos a Hegel, Caxias do Sul, EDUCS, 2005

Em torno à Diferença - aventuras da Alteridade na complexidade da cultura contemporânea, Rio de Janeiro: Lumen Juris, 2007. 
"Justiça, liberdade e alteridade ética. Sobre a questão da radicalidade da justiça desde o pensamento de E. Levinas", in: Veritas, Vol. 46 n. 2, 2001, p. 265-274.

. "Nós e os outros. Sobre a questão do humanismo, hoje", in: PAVIANI, Jayme - DAL RI Jr, Arno (Orgs.), Globalização e humanismo latino, Porto Alegre: EDIPUCRS, 2000, p. 203-212.

. "Três teses sobra a violência", in Civitas - Revista de Ciências Sociais, PUCRS, ano 1, nํ 2,

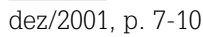

. "Bases filosóficas da bioética e sua categoria fundamental: uma visão contemporânea". Bioética (Brasília), v. 13, p. 11-30, 2007.

. "Por uma estética antropológica desde a ética da Alteridade: do "estado de exceção" da violência sem memória ao "estado de exceção" da excepcionalidade do concreto". Veritas (Porto Alegre), v. 51, p. 129-139, 2006

. "“Pensiero debole", diferença e alteridade: uma releitura". In: Alceu. Revista de ComunicaÇão, Cultura e Política, v. 7, p. 254-273, 2006.

. "A dignidade da pessoa humana; uma visão contemporânea", in: Filosofazer, Passo Fundo, ano XIV, n. 26, p. 7-36, 2005-II.

. "Das neue Denken und die Ermöglichung des Friedens - Franz Rosenzweig und Emmanuel

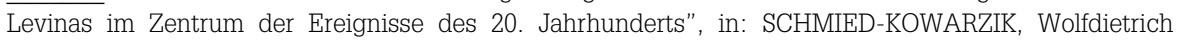
(Org.), Franz Rosenzweig "neues Denken", Vol. I, Freiburg/München: Alber, 2006, p. 583-595.

. "Da lógica do sentido ao sentido da lógica: Levinas encontra Platão", in: Veritas v. 49, n. 4, dezembro 2004, p. 781-801.

"Ética e Ambiente. Por uma nova ética ambiental", in: CLOTET, J. - FEIJÓ, A. - OLIVEIRA, M. G. (Orgs.), Bioética - uma visão panorâmica, Porto Alegre: EDIPUCRS, 2005, p. 235-246.

(Org.) et alii, Ciência e Ética - os grandes desafios, Porto Alegre: EDIPUCRS, 2006.

SOUZA, Ricardo. Timm de. - OLIVEIRA, Nythamar Fernandes de. (Orgs.) Fenomenologia hoje - existência, ser e sentido no alvorecer do século XXI, Porto Alegre: EDIPUCRS, 2001.

Fenomenologia hoje II - significado e linguagem, Porto Alegre: EDIPUCRS, 2002.

. Fenomenologia hoje III - Bioética, Biotecnologia, Biopolítica, porto Alegre: EDIPUCRS, 2007.

SOUZA, Ricardo Timm de. - FARIAS, André Brayner de. - FABRI, Marcelo (Orgs.). Alteridade e ética obra comemorativa dos 100 anos de nascimento de Emmanuel Levinas, Porto Alegre: EDIPUCRS, 2007.

SUSIN, Luiz Carlos. O homem messiânico. Uma introdução ao pensamento de Emmanuel Levinas, Porto Alegre: EST, Petrópolis: Vozes, 1983.

SUSIN, Luiz Carlos et alii (Orgs.). Éticas em Diálogo - Levinas e o pensamento contemporâneo: questões e interfaces, Porto Alegre: EDIPUCRS, 2003.

TIBURI, Márcia. Filosofia Cinza, Porto Alegre: Escritos, 2004.

. Uma outra história da razão, São Leopoldo: Ed. UNISINOS, 2003. 